\title{
Nail Psoriasis and Quality-of-Life Measurement in Clinical Trials: Call for the Use of Nail-Specific Instruments
}

\author{
Christine Blome $^{1}$ (1) $\cdot$ Matthias Augustin $^{1}$ (1) $\cdot$ Toni Maria Klein $^{1}$ (])
}

Accepted: 27 June 2021 / Published online: 12 August 2021

(c) The Author(s) 2021

\begin{abstract}
Nail involvement is frequent in people with psoriasis. It can considerably impair health-related quality of life (HRQoL) beyond the impairments due to other psoriasis symptoms, for example, because patients feel ashamed of visible nail defects or because of the functional impairment in manual activities and walking. In clinical trials on nail psoriasis, it is therefore crucial to assess whether the treatment reduces HRQoL impairments that are specific to nail psoriasis. For this purpose, two validated patient questionnaires are available, the Nail Psoriasis Quality of Life Scale (NPQ10) and the Nail Assessment in Psoriasis and Psoriatic Arthritis-Quality of Life (NAPPA-QOL). The ten-item NPQ10 has the advantage of being short and thus quick to administer. The 20-item NAPPA-QOL, in contrast, assesses the different dimensions of HRQoL which is considered a multi-dimensional construct. Yet most randomized controlled trials on nail psoriasis do not evaluate HRQoL improvement. If they do, a number of different instruments are used, most of which are not nail specific. This makes comparison of trial outcomes difficult. Harmonizing the measurement of HRQoL in future clinical trials on nail psoriasis would improve comparability across studies and would also enhance the reliability of meta-analyses.
\end{abstract}

\section{Key Points}

Patients with nail psoriasis have specific quality-of-life impairments as compared to patients with psoriasis in general.

Quality-of-life impairments that stem specifically from nail involvement in psoriasis should be measured with nail psoriasis-specific and validated questionnaires.

In order to enable comparisons between clinical studies, harmonization of measurement instruments to be used across trials is needed.
Christine Blome

c.blome@uke.de

1 Institute for Health Services Research in Dermatology and Nursing (IVDP), University Medical Center HamburgEppendorf (UKE), Martinistraße 52, 20246 Hamburg, Germany

\section{Quality of Life in People with Nail Psoriasis}

Nail involvement on fingers and/or toes is frequent in psoriasis, with $25 \%$ [1] to $41 \%$ [2] of patients affected. It is also a marker of increased disease severity of psoriasis and psoriasis arthritis [3-5]. Clinically, it can manifest in symptoms such as pitting, nail plate crumbling, or nail thickening and uplifting [6]. Further signs include leukonychia, onychodystrophy, splinter hemorrhages, and oil drops. Nail psoriasis (NPso) comes with considerable patient burden over and above impairments due to other psoriasis symptoms [2, 7, 8]. Firstly, NPso is highly visible, especially when the fingers are affected, resulting in perceptions of stigma, self-consciousness, and social problems. As a consequence, patients often try to hide their nails from others. Secondly, NPso can interfere with walking and with activities involving the fingers, such as manual work, typing, or self-care; this results in impairments at work, during sporting activities, and in everyday life. Thirdly, like other psoriatic lesions, NPso can induce unpleasant sensations such as pain and itch. 


\section{New Targeted Agents}

Nails are considered a hard-to-treat location in psoriasis [1], especially when using topical treatment only. In recent years, targeted systemic treatments such as secukinumab have been shown to improve both clinical NPso severity and health-related quality of life (HRQoL) [9]. In a recent network meta-analysis, six biologics were compared in terms of probability of achieving complete clinical resolution of NPso about half a year after treatment initiation [10]. Outcomes differed greatly between medications, ranging from $0.8 \%$ for infliximab to $46.5 \%$ for ixekizumab. This comparison must be interpreted with caution because - as is typical for network analyses-the included studies were not completely comparable, regarding patient characteristics, outcome measures and others; the authors note that, for example, the effectiveness of infliximab was underestimated. However, the analysis shows that efficacious medication for NPso is available. Another recent meta-analysis [11] found tofacitinib and ixekizumab to effectively reduce clinical severity of NPso. Again, comparability was limited due to the different endpoints and outcome instruments used, with some studies even having to be excluded from the meta-analysis for this reason. This underlines the benefits of using uniform outcome measures across trials.

\section{Outcome Measurement in Clinical Trials in Psoriasis and Nail Psoriasis}

One of the main objectives of psoriasis and NPso treatment, if not the primary objective, is to reduce patient burden. This is why outcomes that should be measured in clinical NPso trials also include HRQoL, which is a multi-dimensional construct covering the impact of disease and treatment on different areas of the patient's life [12]. This typically includes physical, emotional, and social impairments as well as functional limitations in everyday life. Standardized HRQoL questionnaires either focus on the effect of a specific disease (like psoriasis) or disease group (like skin diseases), or on patients in general (generic HRQoL) and must be evaluated for reliability, validity, and responsiveness before being used in clinical trials [13]. Including HRQoL as a trial endpoint is all the more important as clinical severity and quality of life are associated, but far from redundant [14].

However, assessment methods designed for use in skin psoriasis are not sufficiently sensitive to spot the impact of NPso, which is true for both clinical severity and HRQoL instruments. Clinical severity of psoriasis is most commonly measured with the Psoriasis Area and Severity Index (PASI), which weighs by affected body surface area in head, upper limbs, trunk, and lower limbs without nails being considered separately [15]. Nail affection can thus account for a very small increase in PASI scores only. NPso severity is therefore measured with nail-specific instruments like the Nail Psoriasis Severity Index (NAPSI) [16] or the NAPPA Clinical Assessment of Severity (NAPPA-CLIN) [17].

For HRQoL measurement, the skin-specific Dermatology Life Quality Index (DLQI) [18] is the instrument used most commonly in clinical studies on psoriasis [19]. In addition, the Psoriasis Index of Quality of Life (PSORIQoL) questionnaire has been developed for the measurement of psoriasis-specific HRQoL impairment [20]. Neither DLQI nor PSORIQoL fully reflect nail-specific problems such as difficulties working with one's hands.

Not using nail-specific instruments in patients with NPso can have a number of negative consequences. First, patient burden, and thus the need for clinical action, may be underestimated if the specific effects of NPso account for a large part of the patient's HRQoL impairment. Second, treatment effects will be underestimated if the intervention in question specifically benefits the nails and thereby improves nailspecific HRQoL impairments. Third, treatment effects will be overestimated if the intervention mainly improves skin, but not nail symptoms. Neglecting nail-specific impairment can thus lead to suboptimal treatment decisions.

This is why we believe that in clinical practice, NPsospecific HRQoL instruments should be used both in patients with NPso only and in those with both nail and skin symptoms, and that the extra effort for adding these instruments is warranted. In clinical studies that include patients with NPso, nail-specific instruments should be added as a secondary endpoint. If the main target of an intervention is actually NPso improvement, clinical trials need not exclude patients with both nail and body psoriasis in order to specifically assess the effect on NPso as long as all items of the HRQoL instruments are specific to nail impairments (which is the case for both instruments described below).

\section{HRQoL Instruments Specific to Nail Psoriasis}

In order to detect validated questionnaires for the measurement of HRQoL in people with NPso, we conducted a PubMed/Medline search combining search terms on NPso (Fig. 1). The search was conducted on November 30th, 2020. We found two instruments: The Nail Psoriasis Quality of Life Scale (NPQ10) [21] and the Nail Assessment in 


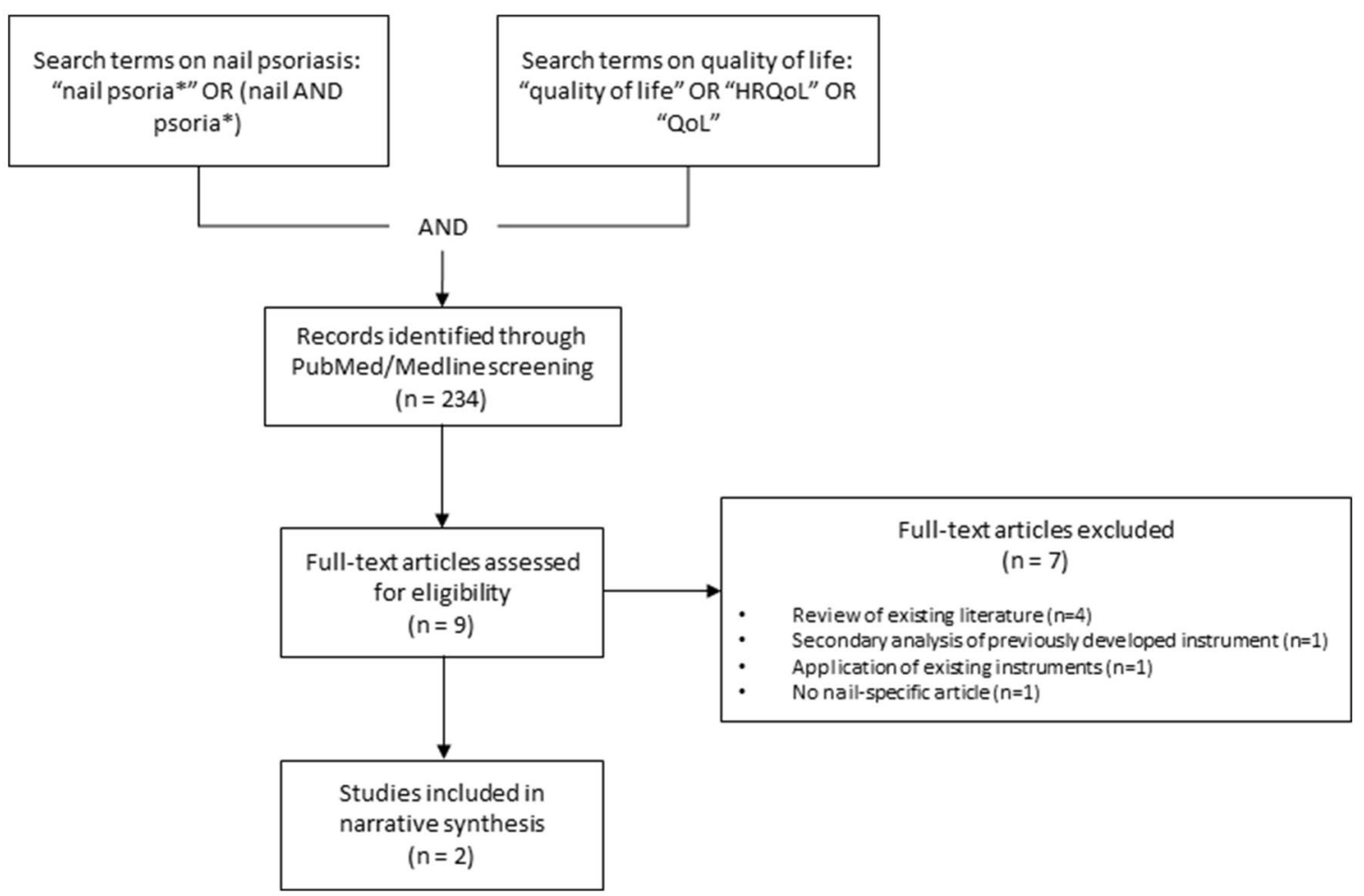

Fig. 1 PubMed/Medline search and selection process for studies to include in the narrative synthesis. $H R Q o L$ health-related quality of life, $Q o L$ quality of life

Psoriasis and Psoriatic Arthritis-Quality of Life (NAPPAQOL) [17].

\subsection{NPQ10}

The NPQ10 [21], as the name suggests, contains only ten items, resulting in a single scale, and has thus the advantage of being brief and quick to administer with little effort for the patients. This can be important in busy clinical life and in studies that assess a high number of different constructs. However, the instrument does not depict the different dimensions of HRQoL, as only a global score on overall HRQoL is calculated. The instrument was developed in France; its items were selected by an expert group including patients. It has been validated in 795 French patients with NPso, demonstrating good internal consistency, test-retest reliability (albeit using a subsample of only 15 patients), and convergent validity with regard to the DLQI and to clinical severity (hands and feet involvement vs. only one of these two).

\subsection{NAPPA-QOL}

The NAPPA-QOL [17] is twice as long as the NPQ10 [21]. The 20 items are assigned to three dimensions (physical aspects, stigma and emotional status, everyday life), which allows for a more differentiated evaluation of impairment in different areas of life. In addition, a global score quantifies overall HRQoL impairment. The NAPPA-QOL was developed and validated in a multi-national project including Denmark, Germany, Italy, Japan, Spain, and the USA. Two authors of this review (C.B. and M.A.) were involved in the development. Items were defined by an expert group including patients, based on a survey in 120 people with NPso. The validation study in 203 patients indicated good internal consistency, convergent validity regarding clinical severity (as measured, among others, by PASI and NAPSI) and both generic and skin-specific HRQoL (DLQI, EQ-5D), and responsiveness. Test-retest reliability is currently being investigated in a psychometric study in Germany.

\subsection{Comparison Between NPQ10 and NAPPA-QOL Content}

The respective content of the two questionnaires is presented in Table 1. There is very little overlap in the exact item content between the two measures: only pain is assessed by both questionnaires. While the NPQ10 focuses more on manual activities, in particular getting dressed, the NAPPA-QOL includes more items on symptoms as well as social and psychological impairments. 
Table 1 Item content of the nail psoriasis-specific HRQoL instruments NPQ10 and NAPPA-QOL

\begin{tabular}{llll}
\hline Item content & NPQ10 & $\begin{array}{l}\text { NAPPA-QOL: } \\
\text { subscale 'Signs' }\end{array}$ & $\begin{array}{l}\text { NAPPA-QOL: } \\
\text { subscale 'Stigma' }\end{array}$
\end{tabular}

Location of nail psoriasis

\section{Symptoms}

Pain

Itch

Reduced strength of the nails

Hardened, thickened, raised nails

Changed nail appearance

Nails looking different

\section{Difficulties with manual activities}

Gripping things

Working with one's hands

Catching one's nails on things

Nail care

Putting on socks

Putting on shoes

Getting dressed (more slowly than usual)

Getting dressed (needing help)

Usual jobs around the house

Big jobs around the house

Turning the door key

Driving the car

\section{Social life/psyche}

Irritable; bad-tempered with people

Depressed/less self-confident

Leisure and sports activities restricted

No normal working life

Burden on relationship

Avoiding to touch other people

Trying to hide nails

Ugly nails

Embarrassment

Other people react negatively

Other people stare $\mathrm{x}$

$\mathrm{x}^{\mathrm{a}}$

$\mathrm{x}$

$\mathrm{x}$

$\mathrm{x}$

$\mathrm{x}$

$\mathrm{x}$

$\mathrm{x}$
$\mathrm{x}$
$\mathrm{x}$
$\mathrm{x}$
$\mathrm{x}$
$\mathrm{x}$
$\mathrm{x}$
$\mathrm{x}$

HRQoL health-related quality of life, NAPPA-QOL Nail Assessment in Psoriasis and Psoriatic Arthritis-Quality of Life, NPQ10 Nail Psoriasis Quality of Life Scale

aOr 'other abnormal sensations'

\section{HRQoL Assessment in Clinical Trials in Nail Psoriasis}

In order to get an overview of how HRQoL is measured in randomized controlled trials (RCTs) on NPso, we also conducted a PubMed/Medline search on January 12th, 2021 (see Fig. 2). We selected studies that either included only patients with NPso or analyzed patients with NPso as a subgroup of the study population, as only in such studies is the use of nail-specific HRQoL instruments considered reasonable, and that assessed HRQoL with any instrument. From the included studies, we extracted information on HRQoL instruments as well as information on any other patient-reported outcome measures used.

Among the 182 publications found with the search terms, 45 were articles on RCTs in patients with NPso. Of these, eight reported on HRQoL outcomes. One of these eight studies had to be excluded as no full text was available [22]. The remaining seven papers (Table 2) reported on five different studies. Publication dates ranged from 2009 to 2020. 


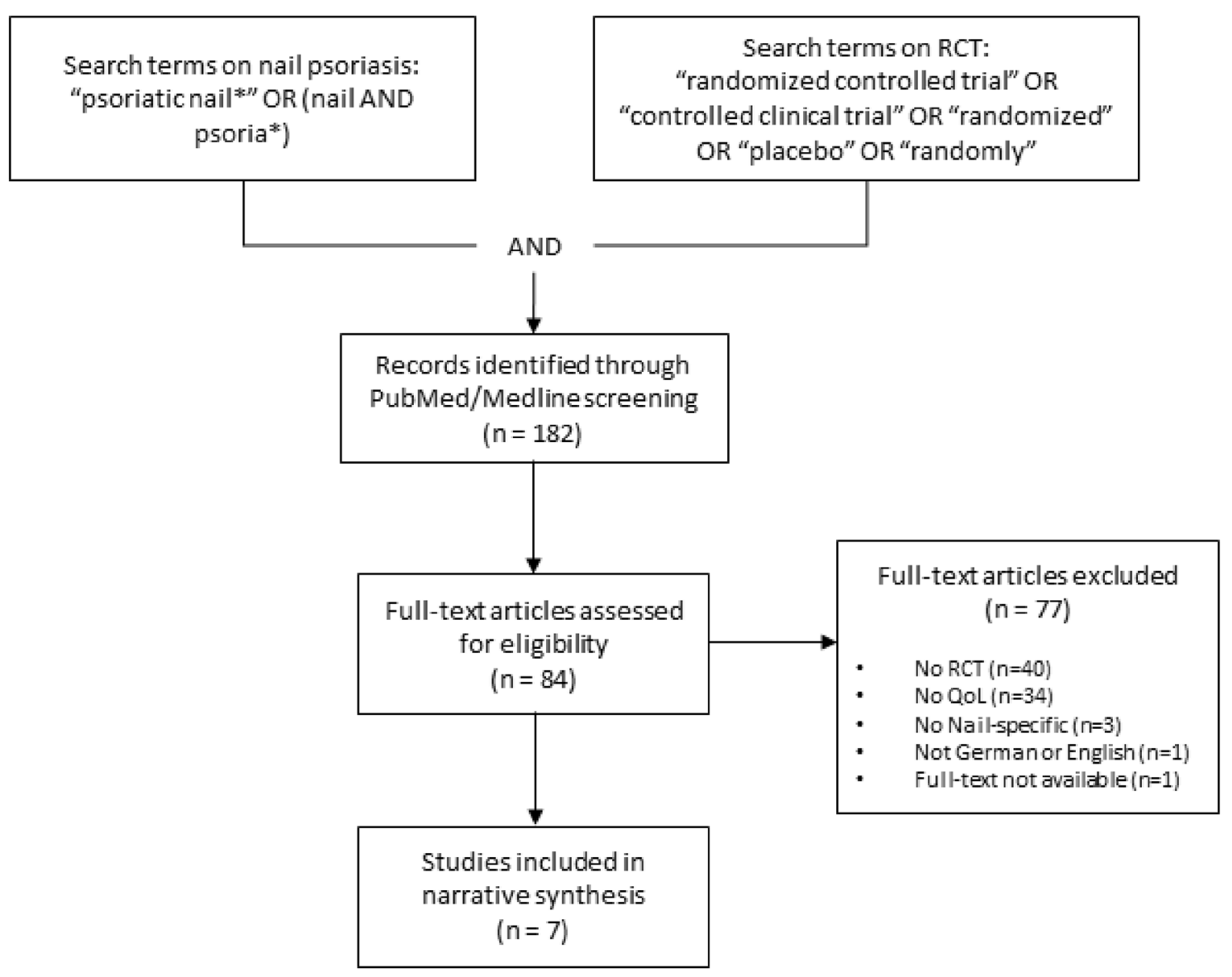

Fig. 2 PubMed/Medline search and selection process to obtain an overview of how HRQoL is measured in RCTs on nail psoriasis. HRQoL health-related quality of life, $Q o L$ quality of life, $R C T$ randomized controlled trial

Between one and three different HRQoL instruments were used in each study. The skin-specific DLQI was used in four studies, two of which used this instrument as the only HRQoL measure (the REACH and the BELIEVE study [23, 24]). A third study used only generic (i.e., not disease-specific) HRQoL instruments in addition to the DLQI, namely the EQ-5D and the SF-36 (the CRYSTAL study [25]). The fourth study added the EQ-5D and the NAPPA-QOL to the DLQI (the TRANSFIGURE study [9, 26]). The remaining RCT was reported in two papers, one of which presented results of the NPQ10 [27] and the other presented results of the NPQ10 and the NAPPA-QOL as HRQoL outcomes [28].

The two trials using NPso-specific HRQoL instruments revealed that the use of adalimumab and secukinumab improved HRQoL [9, 26-28] (Table 3). As this was only a secondary objective in these studies, the scope of reporting on HRQoL differed. While for one study baseline values were reported [27, 28], the TRANSFIGURE study [9, 26] only reported relative improvement without giving baseline values. The latter trial also assessed skin-related and generic HRQoL, for which similar improvement was found.
These findings show that in the majority of RCTs evaluating NPso treatments, no HRQoL findings were reported. If they are reported, this is mostly based on instruments that are not NPso specific. The findings further show that if HRQoL is evaluated, the assessment is not consistent across RCTs. As a consequence, outcomes are only comparable between a subset of trials, which hinders interpretability, but also hampers meta-analyses and indirect comparisons of treatments. With the last-named analysis, one can compare the effectiveness of two different interventions even though they have not been assessed in a head-to-head trial [10,29]. This is possible if both treatments have been tested against the same, third, intervention, which then serves as a common comparator. However, a common outcome parameter is also needed-for example, nail-specific HRQoL.

In the TRANSFIGURE study [9, 26], the Nail Assessment in Psoriasis and Psoriatic Arthritis-Patient Benefit Index (NAPPA-PBI) [17] has been used in addition to the NAPPA-QOL. This instrument assesses the importance of specific treatment goals from the perspective of patients with NPso, and also evaluates the extent to which these goals 
Table 2 Characteristics of randomized controlled trials that reported HRQoL outcomes in nail psoriasis

\begin{tabular}{|c|c|c|c|c|c|c|}
\hline & $\begin{array}{l}\text { Number of } \\
\text { participants }\end{array}$ & Age [M (SD)] & Male $[\%]$ & Treatment & HRQoL instruments used & Further PRO instruments used \\
\hline $\begin{array}{l}\text { Elewski et al. } 2018 \\
\text { [27] }\end{array}$ & 109 & $47.2(11.86)$ & 88.1 & Adalimumab & NPQ10 & $\begin{array}{l}\text { Nail Psoriasis Pain NRS, NPPFS, } \\
\text { B-SNIPI50 }\end{array}$ \\
\hline $\begin{array}{l}\text { Elewski et al. } 2019 \\
\text { [28] }\end{array}$ & 94 & $47.3(11.82)$ & 88.3 & Adalimumab & NPQ10, NAPPA-QOL & $\begin{array}{l}\text { Nail Psoriasis Pain NRS, NPPFS, } \\
\text { B-SNIPI50 }\end{array}$ \\
\hline $\begin{array}{l}\text { Luger et al. } 2009 \\
\text { [25] }\end{array}$ & 564 & 45.3 (NA) & 75.4 & Etanercept & DLQI, EQ-5D, SF-36 & HADS \\
\hline $\begin{array}{l}\text { Poulin et al. } 2014 \\
\text { [23] }\end{array}$ & $\begin{array}{l}13^{\mathrm{a}} \\
10^{\mathrm{b}}\end{array}$ & $\begin{array}{l}56.7(9.48)^{\mathrm{a}} \\
52.9(9.24)^{\mathrm{b}}\end{array}$ & $\begin{array}{l}38.5^{\mathrm{a}} \\
50.0^{\mathrm{b}}\end{array}$ & Adalimumab & DLQI & Psoriasis and PsA pain VAS \\
\hline $\begin{array}{l}\text { Reich et al. } 2019 \\
\text { [26] }\end{array}$ & $\begin{array}{l}66^{\mathrm{c}} \\
67^{\mathrm{d}}\end{array}$ & $\begin{array}{l}45.1(12.9)^{\mathrm{c}} \\
43.5(10.9)^{\mathrm{d}}\end{array}$ & $\begin{array}{l}80^{\mathrm{c}} \\
82^{\mathrm{d}}\end{array}$ & Secukinumab & EQ-5D, DLQI, NAPPA-QOL & $\begin{array}{l}\text { NAPPA-PBI, Subject Goal } \\
\text { Assessment }\end{array}$ \\
\hline $\begin{array}{l}\text { Reich et al. } 2020 \\
\text { [9] }\end{array}$ & $\begin{array}{l}66^{\mathrm{c}} \\
67^{\mathrm{d}}\end{array}$ & $\begin{array}{l}45.1(12.9)^{\mathrm{c}} \\
43.5(10.9)^{\mathrm{d}}\end{array}$ & $\begin{array}{l}80^{\mathrm{c}} \\
82^{\mathrm{d}}\end{array}$ & Secukinumab & EQ-5D, DLQI, NAPPA-QOL & $\begin{array}{l}\text { NAPPA-PBI, Subject Goal } \\
\text { Assessment }\end{array}$ \\
\hline $\begin{array}{l}\text { Thaci et al. } 2015 \\
\text { [24] }\end{array}$ & 457 & $45.6(11.6)$ & 72.6 & Adalimumab & DLQI & Pain VAS \\
\hline
\end{tabular}

Results are reported for those study participants who had received active treatment

$B$-SNIPI5O $\geq 50 \%$ reduction in the scalp component of the Brigham Scalp Nail Inverse Palmo-Plantar Psoriasis Composite Index (an index composed of both patient- and physician-reported data), $D L Q I$ Dermatology Life Quality Index, $E Q-5 D$ HRQoL questionnaire developed by the EuroQoL group, HADS Hospital Anxiety and Depression Scale, HRQoL health-related quality of life, $M$ mean, NA not applicable, NAPSI5O $\geq 50 \%$ reduction in the Nail Psoriasis Severity Index, NAPPA-PBI Nail Assessment in Psoriasis and Psoriatic Arthritis-Patient Benefit Index, NAPPA-QOL Nail Assessment in Psoriasis and Psoriatic Arthritis-Quality of Life, NAPSI Nail Psoriasis Severity Index, NPPFS Nail Psoriasis Physical Functioning Severity, NPQ10 Nail Psoriasis Quality of Life Scale, NRS Numerical Rating Scale, PRO patient-reported outcomes, PsA psoriatic arthritis, $S D$ standard deviation, $S F$-36 36-Item Short-Form Survey, VAS visual analog scale

${ }^{a}$ NAPSI50 responders

${ }^{b}$ NAPSI50 non-responders

${ }^{\mathrm{c}}$ Secukinumab $300 \mathrm{mg}$

${ }^{\mathrm{d}}$ Secukinumab $150 \mathrm{mg}$

have been achieved by NPso treatment. The weighted global score indicates the treatment benefit as perceived by the individual patient, which can complement the data on HRQoL improvement as treatment needs can differ widely from one patient to another [7].

The findings of our literature search match that of a systematic review conducted in 2015 (published in 2018, [30]) that aimed to identify both clinical and patient-reported NPso outcome measures used in RCTs. They found that HRQoL was assessed in $43 \%$ of the included studies, mainly using the DLQI, but also the NPQ10 and the NAPPA-QOL. The authors advocate the development of core outcome sets for NPso, that is, a consensus-derived set of outcomes to be measured and reported in research and/or practice. They suggest this could be done in the context of the International Dermatology Outcome Measures (IDEOM) initiative [31]. IDEOM has recommended HRQoL as a core domain to be measured in all psoriasis clinical trials, and the manifestation 'nail psoriasis' as 'important, but not required' [32]. They did not specify how HRQoL shall be measured, leaving this to future IDEOM working groups; as of May 2021, no such consensus on how to assess HRQoL in psoriasis trials has been published yet.
An earlier systematic review performed in 2009 (published in 2010, [33]) aimed to describe the use of clinical and patient-reported outcome measures in a broader range of NPso study types. It showed that use of patient-reported outcome measures was rare in clinical studies and case reports. As the NPQ10 had first been published in that same year, and the NAPPA-QOL even later, it is not surprising that the review found no use of nail-specific HRQoL instruments; this illustrates the positive development in this field within the last decade.

\section{Conclusion}

HRQoL impairment due to NPso is an important outcome in both clinical care and research. It should be measured with standardized patient questionnaires for which there is evidence of good psychometric properties including reliability, validity, and responsiveness; ideally, these questionnaires should be NPso-specific in order to capture the distinct impairments that come with this condition. In addition, generic and skin-specific questionnaires can be used, 
Table 3 HRQoL results as reported in randomized clinical trials assessing nail psoriasis-specific HRQoL

\begin{tabular}{|c|c|c|}
\hline Reference & Instrument & Results \\
\hline $\begin{array}{l}\text { Elewski et al. } 2018 \\
\text { [27] }\end{array}$ & NPQ10 & $\begin{array}{l}\text { Adalimumab }(n=109) \text {, mean values: baseline: } 5.1 \text {; week } 16: 0.4 \text {; week } 26: 0.6 \\
\text { Placebo }(n=107) \text {, mean values: baseline: } 5.4 \text {; week } 16: 3.1 \text {; week } 26: 3.3 \\
\text { Significant difference between adalimumab and placebo }(p<0.001)\end{array}$ \\
\hline \multirow[t]{2}{*}{$\begin{array}{l}\text { Elewski et al. } 2019 \\
\text { [28] }\end{array}$} & NPQ10 & $\begin{array}{l}\text { Adalimumab, continuing from blinded period (until week } 26 \text { ) to open-label period ( } n=94) \text {, mean values: } \\
\text { baseline: } 4.9 \text {; week } 26 \text { : improvement from baseline by } 3.4 \text { (as observed); week 52: improvement from } \\
\text { baseline by } 4.2 \text { (as observed) }\end{array}$ \\
\hline & NAPPA-QOL & $\begin{array}{l}\text { Adalimumab, continuing from blinded period (until week } 26) \text { to open-label period }(n=94) \text { : baseline: } 3.1 \text {; } \\
\text { week } 26 \text { : mean improvement from baseline by } 1.3 \text { (as observed); week 52: mean improvement from base- } \\
\text { line by } 1.6 \text { (as observed) }\end{array}$ \\
\hline \multirow[t]{3}{*}{$\begin{array}{l}\text { Reich et al. } 2019 \\
\text { [26] }\end{array}$} & NAPPA-QOL & $\begin{array}{l}\text { Secukinumab } 300 \mathrm{mg}(n=66) \text { : week 16: } 59.3 \% \text { median percentage improvement from baseline (no baseline } \\
\text { values reported) } \\
\text { Secukinumab } 150 \mathrm{mg}(n=67) \text { : week 16: } 44.5 \% \text { median percentage improvement from baseline (no baseline } \\
\text { values reported) } \\
\text { Placebo }(n=65) \text { : week } 16: 19 \% \text { median percentage improvement from baseline (no baseline values } \\
\text { reported) } \\
\text { Significant difference between secukinumab } 300 \mathrm{mg} \text { and secukinumab } 150 \mathrm{mg} \text {, respectively, as compared to } \\
\text { placebo (both } p<0.001 \text { ) }\end{array}$ \\
\hline & DLQI & $\begin{array}{l}\text { Secukinumab } 300 \mathrm{mg}(n=66) \text { : week 16: } 62.9 \% \text { DLQI 0/1 (no baseline values reported) } \\
\text { Secukinumab } 150 \mathrm{mg}(n=67) \text { : week 16: } 44.6 \% \text { DLQI 0/1 (no baseline values reported) } \\
\text { Placebo }(n=65) \text { : week 16: 5.1\% DLQI 0/1 (no baseline values reported) } \\
\text { Significant difference between secukinumab } 300 \mathrm{mg} \text { and secukinumab } 150 \mathrm{mg} \text {, respectively, compared with } \\
\text { placebo (both } p<0.001)\end{array}$ \\
\hline & EQ-5D & $\begin{array}{l}\text { Secukinumab } 300 \mathrm{mg}(n=66) \text {, health state as percentage of full health: baseline: } 73 \% \text {; week } 16: 80 \% \\
\text { Secukinumab } 150 \mathrm{mg}(n=67) \text {, health state as percentage of full health: baseline: } 68 \% \text {; week } 16: 85 \% \\
\text { Placebo }(n=65) \text {, health state as percentage of full health: baseline: } 69 \% \text {; week } 16: 60 \%\end{array}$ \\
\hline \multirow[t]{3}{*}{$\begin{array}{l}\text { Reich et al. } 2020 \\
\text { [9] }\end{array}$} & NAPPA-QOL & $\begin{array}{l}\text { Secukinumab } 300 \mathrm{mg}(n=66) \text { : at } 2.5 \text { years: } 52.4 \% \text { mean improvement from baseline (no baseline values } \\
\text { reported) } \\
\text { Secukinumab } 150 \mathrm{mg}(n=67) \text { : at } 2.5 \text { years: } 18.1 \% \text { mean improvement from baseline (no baseline values } \\
\text { reported) }\end{array}$ \\
\hline & DLQI & $\begin{array}{l}\text { Secukinumab } 300 \mathrm{mg}(n=66): \text { at } 2.5 \text { years: } 53.8 \% \text { DLQI } 0 / 1 \text { (no baseline values reported) } \\
\text { Secukinumab } 150 \mathrm{mg}(n=67): \text { at } 2.5 \text { years: } 45.5 \% \text { DLQI } 0 / 1 \text { (no baseline values reported) }\end{array}$ \\
\hline & EQ-5D ${ }^{a}$ & $\begin{array}{l}\text { Secukinumab } 300 \mathrm{mg} \text { ( } n=66 \text { ), per domain, } \% \text { reporting impairments, baseline vs. } 2.5 \text { years: mobility } \\
27.7 \% \text { vs. } 9.2 \% \text {; self-care } 13.8 \% \text { vs. } 0.0 \% \text {; usual activities } 38.5 \% \text { vs. } 12.3 \% \text {; pain/discomfort } 76.9 \% \text { vs. } \\
29.2 \% \text {; depression/anxiety } 46.2 \% \text { vs. } 24.6 \% \\
\text { Secukinumab } 150 \mathrm{mg}(n=67) \text {, per domain, } \% \text { reporting impairments, baseline vs. } 2.5 \text { years: mobility } \\
25.8 \% \text { vs. } 12.1 \% \text {; self-care } 18.2 \% \text { vs. } 7.6 \% \text {; usual activities } 36.4 \% \text { vs. } 12.1 \% \text {; pain/discomfort } 80.3 \% \text { vs. } \\
40.9 \% \text {; depression/anxiety } 57.6 \% \text { vs. } 25.8 \%\end{array}$ \\
\hline
\end{tabular}

$D L Q I$ Dermatology Life Quality Index (range 0-30), DLQI 0/1 DLQI of 0 (indicating no effect at all on a patient's life), EQ-5D HRQoL questionnaire developed by the EuroQoL group, HRQoL health-related quality of life, NPQ10 Nail Psoriasis Quality of Life Scale (range 0-10), NAPPA-QOL Nail Assessment in Psoriasis and Psoriatic Arthritis-Quality of Life (range 0-4)

aPer domain

especially if comparison with other disease groups, for example, people with psoriasis but without nail affection, is required.

Different instruments have been used in NPso trials. A consensus on instruments to be used for the measurement of generic, skin-specific, and NPso-specific HRQoL in future research would greatly improve comparability between trials. For both NPso-specific HRQoL instruments available to date, the NPQ10 and the NAPPA-QOL, good internal consistency and convergent validity have been demonstrated, and both have successfully been used in clinical trials. Both tools have unique advantages: The NAPPA-QOL allows for HRQoL evaluation in different dimensions, has demonstrated responsiveness to change, and is available in 18 country-specific language versions. The NPQ10 is only half as long as the NAPPA-QOL; its test-retest reliability has been supported (in 15 patients), while evaluation of this psychometric property is still pending for the NAPPA-QOL.

Further research is needed for both instruments, in particular on NPQ10 responsiveness and test-retest reliability in a larger sample, and on test-retest reliability of the NAPPAQOL. For both tools, we also recommend investigation of structural validity and measurement invariance using Item Response Theory methods, and of content validity using qualitative methods [34]. We would not recommend the 
development of a new measure unless future research finds that both instruments have severe shortcomings. Instead, we advocate consensus finding on use of one of these two existing instruments as the standard tool to evaluate nail-specific HRQoL in NPso trials.

\section{Declarations}

Funding Open Access funding enabled and organized by Projekt DEAL.

Conflict of interest MA and CB are authors of the NAPPA-QOL instrument, which is presented in this publication. TMK reports no conflict of interest.

Availability of data and material Not applicable.

Code availability Not applicable.

Ethics approval Not applicable.

Consent to participate Not applicable.

Consent for publication Not applicable.

Open Access This article is licensed under a Creative Commons Attribution-NonCommercial 4.0 International License, which permits any non-commercial use, sharing, adaptation, distribution and reproduction in any medium or format, as long as you give appropriate credit to the original author(s) and the source, provide a link to the Creative Commons licence, and indicate if changes were made. The images or other third party material in this article are included in the article's Creative Commons licence, unless indicated otherwise in a credit line to the material. If material is not included in the article's Creative Commons licence and your intended use is not permitted by statutory regulation or exceeds the permitted use, you will need to obtain permission directly from the copyright holder. To view a copy of this licence, visit http://creativecommons.org/licenses/by-nc/4.0/.

\section{References}

1. Egeberg A, See K, Garrelts A, Burge R. Epidemiology of psoriasis in hard-to-treat body locations: data from the Danish skin cohort. BMC Dermatol. 2020;20(1):3. https://doi.org/10.1186/ s12895-020-00099-7.

2. Augustin M, Reich K, Blome C, Schäfer I, Laass A, Radtke MA. Nail psoriasis in Germany: epidemiology and burden of disease. Br J Dermatol. 2010;163(3):580-5. https://doi.org/10.1111/j. 1365-2133.2010.09831.x

3. Prignano F, Rogai V, Cavallucci E, Bitossi A, Hammen V, Cantini F. Epidemiology of psoriasis and psoriatic arthritis in italy-a systematic review. Curr Rheumatol Rep. 2018;20(7):43. https:// doi.org/10.1007/s11926-018-0753-1.

4. Langenbruch A, Radtke MA, Krensel M, Jacobi A, Reich K, Augustin M. Nail involvement as a predictor of concomitant psoriatic arthritis in patients with psoriasis. Br J Dermatol. 2014;171(5):1123-8. https://doi.org/10.1111/bjd.13272.

5. Radtke MA, Langenbruch AK, Schäfer I, Herberger K, Reich K, Augustin M. Nail psoriasis as a severity indicator: results from the
PsoReal study. Patient Relat Outcome Meas. 2011;2:1-6. https:// doi.org/10.2147/PROM.S14861.

6. Bardazzi F, Michela S, Francesca B, Michela M, Bianca MP, Aurora A. Nail psoriasis: an updated review and expert opinion on available treatments, including biologics. Acta Derm Venereol. 2019;99(6):516-23. https://doi.org/10.2340/00015555-3098.

7. Blome C, Costanzo A, Dauden E, Ferrandiz C, Girolomoni G, Gniadecki R, Iversen L, Menter A, Michaelis-Wittern K, Morita A, Nakagawa H, Reich K, Augustin M. Patient-relevant needs and treatment goals in nail psoriasis. Qual Life Res. 2016;25(5):117988. https://doi.org/10.1007/s11136-015-1136-y.

8. van der Velden HM, Klaassen KM, van de Kerkhof PC, Pasch MC. The impact of fingernail psoriasis on patients' health-related and disease-specific quality of life. Dermatology. 2014;229(2):7682. https://doi.org/10.1159/000360696.

9. Reich K, Sullivan J, Arenberger P, Jazayeri S, Mrowietz U, Augustin M, Elewski B, You R, Regnault P, Frueh JA. Secukinumab shows high and sustained efficacy in nail psoriasis: 2.5-year results from the randomized placebo-controlled TRANSFIGURE study. Br J Dermatol. 2020. https://doi.org/10.1111/bjd.19262.

10. Reich K, Conrad C, Kristensen LE, Smith SD, Puig L, Rich P, Sapin C, Holzkaemper T, Koppelhus U, Schuster C. Network meta-analysis comparing the efficacy of biologic treatments for achieving complete resolution of nail psoriasis. J Dermatol Treat 2021;1:1-9. https://doi.org/10.1080/09546634.2021.1892024.

11. Zhang X, Xie B, He Y. Efficacy of systemic treatments of nail psoriasis: a systemic literature review and meta-analysis. Front Med (Lausanne). 2021;8: 620562. https://doi.org/10.3389/fmed. 2021.620562.

12. Forestier B, Anthoine E, Reguiai Z, Fohrer C, Blanchin M. A systematic review of dimensions evaluating patient experience in chronic illness. Health Qual Life Outcomes. 2019;17(1):19. https://doi.org/10.1186/s12955-019-1084-2.

13. Mokkink LB, Terwee CB, Patrick DL, Alonso J, Stratford PW, Knol DL, Bouter LM, de Vet HC. The COSMIN checklist for assessing the methodological quality of studies on measurement properties of health status measurement instruments: an international Delphi study. Qual Life Res. 2010;19(4):539-49. https:// doi.org/10.1007/s11136-010-9606-8.

14. Mattei PL, Corey KC, Kimball AB. Psoriasis Area Severity Index (PASI) and the Dermatology Life Quality Index (DLQI): the correlation between disease severity and psychological burden in patients treated with biological therapies. J Eur Acad Dermatol Venereol. 2014;28(3):333-7. https://doi.org/10.1111/jdv.12106.

15. Fredriksson T, Pettersson U. Severe psoriasis—oral therapy with a new retinoid. Dermatologica. 1978;157:238-44. https://doi.org/ $10.1159 / 000250839$.

16. Rich P, Scher RK. Nail Psoriasis Severity Index: a useful tool for evaluation of nail psoriasis. J Am Acad Dermatol. 2003;49(2):206-11. https://doi.org/10.1067/s0190-9622(03) 00910-1.

17. Augustin M, Blome C, Costanzo A, Dauden E, Ferrandiz C, Girolomoni G, Gniadecki R, Iversen L, Menter A, Michaelis-Wittern K, Morita A, Nakagawa H, Reich K. Nail assessment in psoriasis and psoriatic arthritis (NAPPA): development and validation of a tool for assessment of nail psoriasis outcomes. Br J Dermatol. 2014;170:591-8. https://doi.org/10.1111/bjd.12664.

18. Finlay AY, Khan GK. Dermatology Life Quality Index (DLQI)—a simple practical measure for routine clinical use. Clin Exp Dermatol. 1994;19(3):210-6. https://doi.org/10.1111/j.1365-2230.1994. tb01167.x.

19. Ali FM, Cueva AC, Vyas J, Atwan AA, Salek MS, Finlay AY, Piguet V. A systematic review of the use of quality-of-life instruments in randomized controlled trials for psoriasis. Br J Dermatol. 2017;176(3):577-93. https://doi.org/10.1111/bjd.14788. 
20. McKenna SP, Cook SA, Whalley D, Doward LC, Richards HL, Griffiths CE, Van Assche D. Development of the PSORIQoL, a psoriasis-specific measure of quality of life designed for use in clinical practice and trials. Br J Dermatol. 2003;149(2):323-31. https://doi.org/10.1046/j.1365-2133.2003.05492.x.

21. Ortonne JP, Baran R, Corvest M, Schmitt C, Voisard JJ, Taieb C. Development and validation of Nail Psoriasis Quality of Life Scale (NPQ10). J Eur Acad Dermatol Venereol. 2010;24(1):22-7. https://doi.org/10.1111/j.1468-3083.2009.03344.x.

22. Goldust M, Raghifar R. Clinical trial study in the treatment of nail psoriasis with pulsed dye laser. J Cosmet Laser Ther. 2013. https:// doi.org/10.3109/14764172.2013.854627.

23. Poulin Y, Crowley JJ, Langley RG, Unnebrink K, Goldblum OM, Valdecantos WC. Efficacy of adalimumab across subgroups of patients with moderate-to-severe chronic plaque psoriasis of the hands and/or feet: post hoc analysis of REACH. J Eur Acad Dermatol Venereol. 2014;28(7):882-90. https://doi.org/10.1111/jdv. 12198.

24. Thaçi D, Unnebrink K, Sundaram M, Sood S, Yamaguchi Y. Adalimumab for the treatment of moderate to severe psoriasis: subanalysis of effects on scalp and nails in the BELIEVE study. J Eur Acad Dermatol Venereol. 2015;29(2):353-60. https://doi. org/10.1111/jdv.12553.

25. Luger TA, Barker J, Lambert J, Yang S, Robertson D, Foehl J, Molta CT, Boggs R. Sustained improvement in joint pain and nail symptoms with etanercept therapy in patients with moderate-tosevere psoriasis. J Eur Acad Dermatol Venereol. 2009;23(8):896904. https://doi.org/10.1111/j.1468-3083.2009.03211.x.

26. Reich K, Sullivan J, Arenberger P, Mrowietz U, Jazayeri S, Augustin M, Parneix A, Regnault P, You R, Milutinovic M. Effect of secukinumab on the clinical activity and disease burden of nail psoriasis: 32-week results from the randomized placebo-controlled TRANSFIGURE trial. Br J Dermatol. 2019;181(5):95466. https://doi.org/10.1111/bjd.17351.

27. Elewski BE, Okun MM, Papp K, Baker CS, Crowley JJ, Guillet G, Sundaram M, Poulin Y, Gu Y, Geng Z, Williams DA, Rich PA.
Adalimumab for nail psoriasis: efficacy and safety from the first 26 weeks of a phase 3, randomized, placebo-controlled trial. J Am Acad Dermatol. 2018;78(1):90-99.e1. https://doi.org/10.1016/j. jaad.2017.08.029

28. Elewski BE, Baker CS, Crowley JJ, Poulin Y, Okun MM, Calim$\lim$ B, Geng Z, Reyes Servin O, Rich PA. Adalimumab for nail psoriasis: efficacy and safety over 52 weeks from a phase-3, randomized, placebo-controlled trial. J Eur Acad Dermatol Venereol. 2019;33(11):2168-78. https://doi.org/10.1111/jdv.15793.

29. Signorovitch JE, Wu EQ, Yu AP, Gerrits CM, Kantor E, Bao Y, Gupta SR, Mulani PM. Comparative effectiveness without headto-head trials: a method for matching-adjusted indirect comparisons applied to psoriasis treatment with adalimumab or etanercept. Pharmacoeconomics. 2010;28(10):935-45. https://doi.org/ 10.2165/11538370-000000000-00000.

30. Busard CI, Nolte JYC, Pasch MC, Spuls PI. Reporting of outcomes in randomized controlled trials on nail psoriasis: a systematic review. Br J Dermatol. 2018;178(3):640-9. https://doi.org/10. 1111/bjd.15831.

31. Perez-Chada LM, Merola JF, Armstrong AW, Garg A, Latella J, Gottlieb AB. Report from the International Dermatology Outcome Measures Initiative. J Investig Dermatol Symp Proc. 2020;20(1):S80-3. https://doi.org/10.1016/j.jisp.2020.05.004.

32. Callis Duffin K, Merola JF, Christensen R, Latella J, Garg A, Gottlieb AB, Armstrong AW. Identifying a core domain set to assess psoriasis in clinical trials. JAMA Dermatol. 2018;154(10):113744. https://doi.org/10.1001/jamadermatol.2018.1165.

33. Augustin M, Ogilvie A. Methods of outcomes measurement in nail psoriasis. Dermatology. 2010;221(Suppl 1):23-8. https://doi.org/ 10.1159/000316177.

34. Mokkink LB, Prinsen CAC, Patrick DL, Alonso J, Bouter LM, de Vet HCW, Terwee CB. COSMIN study design checklist for Patient-reported outcome measurement instruments. 2019. https:// www.cosmin.nl/wp-content/uploads/COSMIN-study-designingchecklist_final.pdf. Accessed 2 June 2021. 